\title{
Weighted Points and Lines in Projective Plane of order 17
}

\section{Ban A. Qassim}

College of Computer Sciences and Mathematics

University of Mosul, Iraq

\section{Received on: 11/10/2006}

\section{ABSTRACT}

Makbola. J. Mohamed

College of Engineering

Accepted on: 24/12/2006

In the current research, the points and lines of the projective plane of the seventeenth (17th)order were constructed, this was followed by examining the arcs designated $(\mathrm{k}, \mathrm{n} ; \mathrm{f})$ - in the plane type $(\mathrm{m}, \mathrm{n})$. As a result, it is concluded that these arcs do exist having all their points of the order one or two ,but the order of their lines are $m$ or $n$ only .A further result was arriving at proving the theorems being concluded. The research also included a study of Monoidal arcs with some given examples.

Keywords: projective plane, Monoidal arcs.

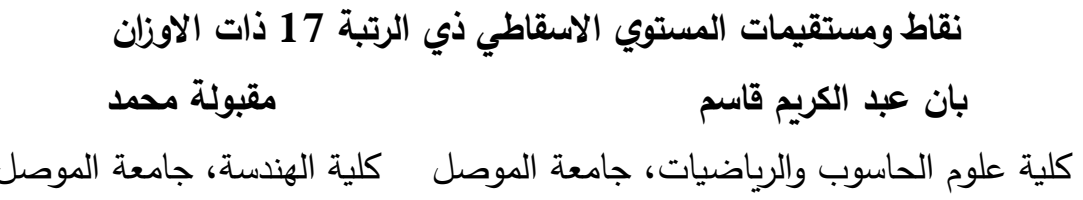

تاريخ القبول: 2006/12/24

تاريخ الاستلام: 2006/10/11

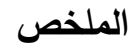

في هذا البحث تم تركيب نقاط ومستقيمات المستوي الأسقاطي ذي الرتبة السابعة عشرة ثم

حاولنا دراسة القوس - (k,n;f) في هذا المستوي ومن النوع (m,n) وتوصلنا إلى إثبات وجود تلك لكاتك

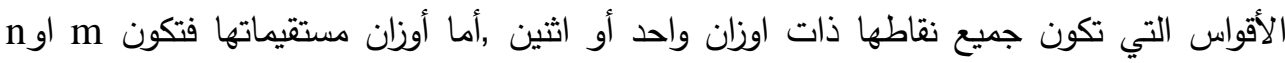

فقط,مع إعطاء برهان للنظريات التي تم استتاجها .وكذلك تتاول البحث دراسة للأقواس الأحادية في

هذا المستوي وأعطينا بعض الأمثلة على ذلك. بلك.

الكلمات المفتاحية: المستوي الأسقاطي، الأقواس الأحادية.

\section{1- Introduction:}

The existence of (k,n;f)- arcs is studied by D' Agostini .Also [8], [6], [7], and [4] study the existance of these arcs in the projective plane of order $3,5,7$ and 9 , respectively.

In this paper, we studied the existance of $(\mathrm{k}, \mathrm{n} ; \mathrm{f})$ - arcs in projective plane of order seventeen .

To explain this work we need first the following introduction about the projective plane $\pi$.

If $\mathrm{f}$ is a function from the set of points of the projective plane $\pi$ in to the set of natural number $\mathrm{N}$, the value $\mathrm{f}(\mathrm{p})$ is called the weight point $\mathrm{p}$ and $\mathrm{F}$ 
is a function from the set of lines of $\pi$ in to $N$, the value $F(L)$ is called the weight line $\mathrm{L}$, i.e $\mathrm{F}(\mathrm{L})=\sum_{p \in L} \mathrm{f}(\mathrm{p})$.

A ( $k, n ; f)-\operatorname{arc}$ Kof $\pi$ is a set of $k$ points such that $K$ does not contain any points of weight zero.

The line $L$ of $\pi$ is called $i$-secant if the total weight of $L$ is $i, X_{j}$ denotes the number of the points having weight $\mathrm{j}$ for $\mathrm{j}=0,1,2, \ldots \ldots, \mathrm{v}$ (where $v=\max _{p \in k} f(p)$ ) and we used $W_{i}^{j}$ for the number of lines of weight $i$ through a point of weight $j$; we also denote that the number of lines of weight $i$ is $\mathrm{Z}_{\mathrm{i}}$, the integers $\mathrm{Z}_{\mathrm{i}}$ are called the characters of $\mathrm{K}$. If the points in the plane are only of weight zero and one, then $\mathrm{K}$ is a $(\mathrm{k}, \mathrm{n})$-arc.

Let $\mathrm{V}$ denote the total weight of $\mathrm{K}$, so by [2] we have:

$$
m(q+1) \leq V \leq(n-v)(q+1)+v------(i) \text {. }
$$

Arcs for which equality holds on the left are called minimal and arcs for which equality holds on the right are called maximal also [2] has proved to be a necessary condition for the existence of a $(k, n ; f)$-arc $K$ of type $(m$, n), $0<\mathrm{m}<\mathrm{n}$ is that

$$
\mathrm{q} \equiv 0 \bmod (\mathrm{n}-\mathrm{m})------(\mathrm{ii})
$$

and

$$
\mathrm{v}=\mathrm{n}-\mathrm{m}
$$

\section{2- $(k, n ; f)-\operatorname{arc}$ of type $(n-17, n)$ with $\mathrm{Li}>0, i=0,1,2, L j=0, j=3, \ldots \ldots, 17$.}

From [1], a $(k, n ; f)-$ arc of type $(m, n)$ requires that $q \equiv 0 \bmod (n-m)$, $\mathrm{m}>0, \mathrm{v} \leq \mathrm{n}-\mathrm{m}$ and $(\mathrm{n}-\mathrm{v})(\mathrm{q}+1) \leq \mathrm{V} \leq(\mathrm{n}-\mathrm{v})(\mathrm{q}+1)+\mathrm{v}$.

For a $(k, n ; f)-a r c$ of type $(n-17, n)$ with $n-m=17$ and for discussion of maximality and minimality of this arc, we study the following conditions:

$$
X_{0}>0, X_{1}>0, X_{2}>0, X_{i}=0 \text {, for } i=3, \ldots . ., 17 .
$$

For minimal $V=(n-17)(q+1)$, from $([6], p .12)$ we deduce that:

$$
\left.\begin{array}{ll}
\mathrm{W}_{\mathrm{n}-17^{0}}=\mathrm{q}+1 & \mathrm{~W}_{\mathrm{n}}{ }^{0}=0 \\
\mathrm{~W}_{\mathrm{n}-17^{1}}=(16 / 17) \mathrm{q}+1 & \mathrm{~W}_{\mathrm{n}}{ }^{1}=(1 / 17) \mathrm{q} \\
\mathrm{W}_{\mathrm{n}-17^{2}}=(15 / 17) \mathrm{q}+1 & \mathrm{~W}_{\mathrm{n}}{ }^{2}=(2 / 17) \mathrm{q}
\end{array}\right\}
$$

\section{Lemma (2-1):}

There is no point of weight zero on any n-secants of a $(k, n ; f)$-arc.

Proof: Follows from equation (1), since $\mathrm{Wn}^{0}=0 . \#$

Theorem(2-2): The total number of n-secants and (n-17)- secants of the $(\mathrm{k}, \mathrm{n} ; \mathrm{f})$-arc of type $(\mathrm{n}-17, \mathrm{n})$ in PG $(2,17)$ is:

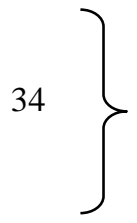




$$
\begin{aligned}
& Z_{n}=(1 / 17)(n-17) q \\
& \text { and } \\
& Z_{n-17}=(1 / 17)\left(17 q^{2}+34 q-n q+17\right)
\end{aligned}
$$

\section{Proof :}

Let $Z_{n-17}$ be the number of lines of weight $n-17$ and $Z_{n}$ the number of lines of weight $n$; then

$$
\begin{aligned}
& Z_{n-17}+Z_{n}=q^{2}+q+1 \\
& (n-17) Z_{n-17}+n Z n=V(q+1)=(n-17)(q+1)^{2}
\end{aligned}
$$

solving equations $(\mathrm{a} 1) \&(\mathrm{a} 2)$ we get

$$
\begin{aligned}
& \mathrm{Zn}=1 / 17(\mathrm{n}-17) \mathrm{q} \\
& \mathrm{Z}_{\mathrm{n}-17}=1 / 17\left(17 \mathrm{q}^{2}+34 \mathrm{q}-\mathrm{nq}+17\right) . \#
\end{aligned}
$$

Now let $\mathrm{Y}$ be an n-secants and suppose that on $\mathrm{Y}$ there are a points of weight two and $\mathbf{b}$ points of weight one.The counting points of $Y$, gives the following:

$$
a+b=q+1
$$

and the weight of points of $\mathrm{Y}$ is

$$
\begin{aligned}
& 2 \mathrm{a}+\mathrm{b}=\mathrm{n} \\
& \text { so, we get } \\
& \mathrm{b}=2(\mathrm{q}+1)-\mathrm{n} \\
& \mathrm{a}=\mathrm{n}-(\mathrm{q}+1)
\end{aligned}
$$

Counting the incidences between points of weight 1and n- secant gives:

$\mathrm{X}_{1} \mathrm{~W}_{\mathrm{n}}{ }^{1}=\mathrm{Z}_{\mathrm{n}} \mathrm{b}$

by using equation (1),(2) \& (3), we have:

$X_{1}=(n-17)(2 q+2-n)$

Simillarly, counting incidence between points of weight 2 and the nsecants gives:

$\mathrm{X}_{2} \mathrm{~W}_{\mathrm{n}}{ }^{2}=\mathrm{Z}_{\mathrm{n}}$ a

Hence using (1), (2) \& (3), we have:

$\mathrm{X}_{2}=[(\mathrm{n}-17)(\mathrm{n}-\mathrm{q}-1)] / 2$

Since

$X_{0}+X_{1}+X_{2}=q^{2}+q+1$

then by using equations(4) \& (5), we get

$2 q^{2}+(53-3 n) q+n^{2}-20 n+53-2 X_{0}=0$

For a solution of $\mathrm{q}$ in $(6)$, we require

$(\mathrm{n}-79)^{2}-\left(3856-16 \mathrm{X}_{0}\right)$ is a square 
that is : $\delta^{2}=(\mathrm{n}-79)^{2}-\left(3856-16 \mathrm{X}_{0}\right)$

\section{3-Arcs in PG(2,17):}

Let $\mathrm{PG}(2,17)$ be a projective plane of order 17.From([5]chapter-3), we attained that this plane contains 307 points, 307 lines, 18 points on every line and 18 lines through every point.

Let $\mathrm{L}_{1}$ be the line which contains the points: $(1,2,10,16,87,110$, $120,152,176,180,192,211,233,254,259,272,279,306)$.

The line $\mathrm{L}_{2}$ can be obtain by adding one to each number of the line $\mathrm{L}_{1}$ to get $\mathrm{L}_{2}(2,3,11,17,88,111,121,153,177,181,193,212,234,255,260$, $273,280,307)$.

Simillarly we can find all others 305 lines of this plane by adding in each step one to get the other line.

\section{4-(150,29;f)-arc of type $(12,29)$ in PG(2,17).}

To find this arc we need to find the value of $\mathrm{X}_{0}$ which makes equation (7) be a square and then find from it $\mathrm{n}$ and $\delta$ i.e we try to check $\mathrm{X}_{0}$ from 1 to 307 and after a large number of efforts we found that, when $\mathrm{X}_{0}=157$, we get $\delta=34$ and $\mathrm{n}=29$, and from (6) we have $\mathrm{q}=17$, which means that $(k, n ; f)$-arc of type $(m, n)$ exist in PG $(2,17)$.

From (4) and (5), we get

$\mathrm{X}_{1}=84$ and $\mathrm{X}_{2}=66$

Which implies that this arc is $(150,29 ; \mathrm{f})$-arc of type $(12,29)$ and the point of weight 0 form $(157,12)$-arc in PG $(2,17)$.

\section{5-Classification of the lines of the plane with respect to the $(150,29 ; f)$ - arc of type $(12,29)$.}

Let $\mathrm{L}$ be 12 -secant having on it a points of weight 2 , $\mathbf{b}$ points of weight 1 and $\mathbf{c}$ points of weight zero, then

$a+b+c=18$

and the weights of the points on $\mathrm{L}$ gives

$2 \mathrm{a}+\mathrm{b}=12$

Let $\mathrm{N}$ be an 29 -secant of a $(150,29 ; \mathrm{f})$-arc, since there are no points of weight 0 on a 29 -secant because $\mathrm{W}_{\mathrm{n}}{ }^{0}=0$, then we can assume that on $\mathrm{N}$ there are a points of weight 2 and $\mathbf{b}$ points of weight 1 , then $a+b=18$ and the weight of points on $\mathrm{N}$ gives:

$2 \mathrm{a}+\mathrm{b}=29$

so $\mathrm{a}=11$ and $\mathrm{b}=7$

and by solving equation (8) \& (9), we have the following lemma. 
Lemma (5-1): The lines of PG $(2,17)$ are partitioned in to eight classes with respect to a minimal $(150,29 ; \mathrm{f})$-arc of type $(12,29)$ as in table-1

Table -1

\begin{tabular}{|c|c|c|c|}
\hline Type of the lines & $\mathrm{a}$ & $\mathrm{b}$ & $\mathrm{c}$ \\
\hline $\mathrm{L}_{0}$ & 0 & 12 & 6 \\
\hline $\mathrm{L}_{1}$ & 1 & 10 & 7 \\
\hline $\mathrm{L}_{2}$ & 2 & 8 & 8 \\
\hline $\mathrm{L}_{3}$ & 3 & 6 & 9 \\
\hline $\mathrm{L}_{4}$ & 4 & 4 & 10 \\
\hline $\mathrm{L}_{5}$ & 5 & 2 & 11 \\
\hline $\mathrm{L}_{6}$ & 6 & 0 & 12 \\
\hline $\mathrm{L}_{7}$ & 11 & 7 & 0 \\
\hline
\end{tabular}

\section{Corollary(5-1-1):}

There is no point of weight 1 on the 12 - secant of $(157,12)$ - arc.

Corollary(5-1-2): There is no point of weight 2 on the 6- secant of $(157,12)-$ arc.

Lemma(5-2): For the existence of $(150,29 ; f)-\operatorname{arc} K$ of type $(12,29)$ with 157 points of weight zero in $\operatorname{PG}(2,17)$, we have the following:

1 - The number $Z_{29}$ of 29- secants of $\mathrm{K}$ is 12 .

2- The number $Z_{12}$ of 12 - secants of $K$ is 295 .

3 - The number $X_{2}$ of points of weight 2 is 66 .

4- The number $X_{1}$ of points of weight 1 is 84 .

Proof:

Follows from equations (2), (4) \& (5).\#

Lemma(5-3): No thirteen points of weight zero can be collinear.

Proof:

Let $\mathrm{L}$ be 13- secant having on it 13 points of weight 0 , then the remaining points of $\mathrm{L}$ is five, if all these points of weight 2 we get the weight of the line $\mathrm{L}$ is ten which is a contraduction. Since the weight of $\mathrm{L}$ is 12.\#

Corollary(5-3-1): The points of weight 0 form $(157,12)$-arc in PG(2,17).

6- Monoidal arc: In this section we consider (k,n;f)- arc which have only one point of weight greater than one, such arcs are called monoidal arcs, i.e a $(k, n ; f)-$ arc is called monoidal if $\operatorname{Imf}=\{0,1, v\}$ and $X_{v}=1$.

Example( 6-1): An example of a monoidal arc can be obtained as follows: 
From (6) when $\mathrm{X}_{0}=272$ and $\mathrm{n}=19$, we get $\mathrm{q}=17$, and from (4) \& (5), we have $X_{1}=34 \& X_{2}=1$ i.e there is a $(35,19 ; f)$ - arc of type $(2,19)$ in $\mathrm{PG}(2,17)$ consists of the following points :

Pi for $\mathrm{i}=\{3,4,12,18,89,112,122,154,178,182,194,213,235,256,261$, $274,281,1,19,27,33,104,127,137,169,193,197,209,228,250,271$, $276,289,296,16\}$

with $\mathrm{V}\left(\mathrm{p}_{\mathrm{i}}\right)=1$ for $\mathrm{i}=\{3,4,12,89,112,122,154,178,182,194,213,235$, 256, 261, 274, 281, 1, 19, 27, 33, 104, 127, 137, 169, 193, 197, 209, 228, $250,271,276,289,296,16\}$

and $\mathrm{V}\left(\mathrm{p}_{\mathrm{i}}\right)=2$, for $\mathrm{i}=18$

and the other points of the plane are of weight zero and form $(272,17)$-arc

The lines of this arc are 17-secants, 16- secants and 0- secants and

1 - The number of 17 -secants are 16.

2- The number of 16-secants are 289.

3 - The number of 0 -secants are 2.

so the total number is 307 .

see table-2.

Since table-2 contains 307 lines, so it is not suitable to write it completly.For this reason it is enough to write only the first twenty lines of the plane and the last twenty lines of it.

Lemma (6-2): There is one point of weight 2 on each 17-secants of $(272,17)-$ arc .

\section{Proof:}

Let $\mathrm{L}$ be 17 -secants of $(272,17)$-arc and having two points of weight 2 , then the weight of $\mathrm{L}$ because 4 and this is a contraduction because the weight of all lines of the plane is either 2 or 19 .\#

Corollary(6-2-1): There is no point of weight 1 on each 17- secants of $(272,17)-$ arc.

Lemma (6-3): There is no point of weight 2 on each 16- secant of $(272,17)$ arc.

\section{Proof:}

Let $\mathrm{L}$ is 16- secant line the remaining points of $\mathrm{L}$ is two .If one of these two points of weight 2 means that the weight of $L$ is 3 , which is a contraduction as in the previous lemma.\#

Corollary(6-3-1): There are two points of weight 1 on each (16-secant ) line of $(272,17)-$ arc.

Theorem(6-4): Each 0- secants line of $(272,17)$ - arc contains one point of weight 2 and seventeen points of weight 1 . 
Proof:From lemma (2-1), and type $(2,19)$ of these lines, we know that the weight of each 0 - secant line is 19 , this means that each 0 - secant line must be contain one point of weight 2 and 17 points of weight 1 .\# see table -2 .

In this table we have:

1- The star points are points of weight 2.

2- The underlined blodface points are points of weight 1.

3- The other points are of weight zero. 
Table (1)

\begin{tabular}{|c|c|c|c|c|c|c|c|c|c|c|c|c|c|c|c|c|c|c|c|c|}
\hline Lines & \multicolumn{18}{|c|}{ Points } & Type & $\mathrm{V}\left(\mathrm{L}_{\mathrm{j}}\right)$ \\
\hline $\mathrm{L}_{288}$ & 288 & 289 & 297 & 303 & 67 & 90 & 100 & 132 & 156 & 160 & 172 & 191 & 213 & 234 & 239 & 252 & 259 & 286 & 16-secant & 2 \\
\hline $\mathrm{L}_{289}$ & $\underline{289}$ & 290 & 298 & 304 & 68 & 91 & 101 & 133 & 157 & 161 & 173 & 192 & $\overline{214}$ & 235 & 240 & 253 & 260 & 287 & 16-secant & 2 \\
\hline $\mathrm{L}_{290}$ & 290 & 291 & 299 & 305 & 69 & 92 & 102 & 134 & 158 & 162 & 174 & 193 & 215 & 236 & 241 & 254 & 261 & 288 & 16-secant & 2 \\
\hline $\mathrm{L}_{291}$ & 291 & 292 & 300 & 306 & 70 & 93 & 103 & 135 & 159 & 163 & 175 & 194 & 216 & 237 & 242 & 255 & $\overline{262}$ & 289 & 16-secant & 2 \\
\hline $\mathrm{L}_{292}$ & 292 & 293 & 301 & 307 & 71 & 94 & 104 & 136 & 160 & 164 & 176 & 195 & 217 & 238 & 243 & $\underline{256}$ & 263 & 290 & 16-secant & 2 \\
\hline $\mathrm{L}_{293}$ & 293 & 294 & 302 & $\underline{1}$ & 72 & 95 & 105 & 137 & 161 & 165 & 177 & 196 & 218 & 239 & 244 & 257 & 264 & 291 & 16-secant & 2 \\
\hline $\mathrm{L}_{294}$ & 294 & 295 & 303 & 2 & 73 & 96 & 106 & 138 & 162 & 166 & 178 & 197 & 219 & 240 & 245 & 258 & 265 & 292 & 16-secant & 2 \\
\hline $\mathrm{L}_{295}$ & 295 & 296 & 304 & $\underline{3}$ & 74 & 97 & 107 & 139 & 163 & 167 & 179 & 198 & 220 & 241 & 246 & 259 & 266 & 293 & 16-secant & 2 \\
\hline $\mathrm{L}_{296}$ & $\underline{296}$ & 297 & 305 & $\underline{4}$ & 75 & 98 & 108 & 140 & 164 & 168 & 180 & 199 & 221 & 242 & 247 & 260 & 267 & 294 & 16-secant & 2 \\
\hline $\mathrm{L}_{297}$ & 297 & 298 & 306 & 5 & 76 & 99 & 109 & 141 & 165 & 169 & 181 & 200 & 222 & 243 & 248 & 261 & 268 & 295 & 16-secant & 2 \\
\hline $\mathrm{L}_{298}$ & 298 & 299 & 307 & 6 & 77 & 100 & 110 & 142 & 166 & 170 & 182 & 201 & 223 & 244 & 249 & 262 & 269 & 296 & 16-secant & 2 \\
\hline $\mathrm{L}_{299}$ & 299 & 300 & $\underline{1}$ & 7 & 78 & 101 & 111 & 143 & 167 & 171 & 183 & 202 & 224 & 245 & 250 & 263 & 270 & 297 & 16-secant & 2 \\
\hline $\mathrm{L}_{300}$ & 300 & 301 & 2 & 8 & 79 & 102 & $\underline{112}$ & 144 & 168 & 172 & 184 & 203 & 225 & 246 & 251 & 264 & 271 & 298 & 16-secant & 2 \\
\hline $\mathrm{L}_{301}$ & 301 & 302 & $\underline{3}$ & 9 & 80 & 103 & 113 & 145 & 169 & 173 & 185 & 204 & 226 & 247 & 252 & 265 & 272 & 299 & 16-secant & 2 \\
\hline $\mathrm{L}_{302}$ & 302 & 303 & $\underline{4}$ & 10 & 81 & 104 & 114 & 146 & 170 & 174 & 186 & 205 & 227 & 248 & 253 & 266 & 273 & 300 & 16-secant & 2 \\
\hline $\mathrm{L}_{303}$ & 303 & 304 & 5 & 11 & 82 & $\overline{105}$ & 115 & 147 & 171 & 175 & 187 & 206 & 228 & 249 & 254 & 267 & 274 & 301 & 16-secant & 2 \\
\hline $\mathrm{L}_{304}$ & 304 & 305 & 6 & $\underline{12}$ & 83 & 106 & 116 & 148 & 172 & 176 & 188 & 207 & 229 & 250 & 255 & 268 & 275 & 302 & 16-secant & 2 \\
\hline $\mathrm{L}_{305}$ & 305 & 306 & 7 & 13 & 84 & 107 & 117 & 149 & 173 & 177 & 189 & 208 & 230 & 251 & 256 & 269 & 276 & 303 & 16-secant & 2 \\
\hline $\mathrm{L}_{306}$ & 306 & 307 & 8 & 14 & 85 & 108 & 118 & 150 & 174 & 178 & 190 & 209 & 231 & 252 & 257 & 270 & 277 & 304 & 16-secant & 2 \\
\hline $\mathrm{L}_{307}$ & 307 & $\underline{1}$ & 9 & 15 & 86 & 109 & 119 & 151 & 175 & 179 & 191 & 210 & 232 & 253 & 258 & 271 & 278 & 305 & & \\
\hline
\end{tabular}

Table-2

\begin{tabular}{|c|c|c|c|c|c|c|c|c|c|c|c|c|c|c|c|c|c|c|c|c|}
\hline Lines & & & & \\
\hline $\mathrm{L}_{1}$ & 1 & & & & & & & & & & & & & & & & & & Type & $\mathrm{V}\left(\mathrm{L}_{\mathrm{J}}\right.$ \\
\hline $\mathrm{L}_{2}$ & 2 & 3 & & & & & & & 176 & 180 & 192 & 211 & 233 & 254 & 259 & 272 & 279 & 306 & 16-secant & 2 \\
\hline $\mathrm{L}_{3}$ & 3 & & & & 88 & 111 & 121 & 153 & 177 & 181 & $\underline{193}$ & 212 & 234 & 255 & 260 & 273 & 280 & 307 & 16-secant & 2 \\
\hline $\mathrm{L}_{4}$ & $\overline{4}$ & & & & $\underline{89}$ & $\underline{112}$ & $\underline{122}$ & 154 & 178 & 182 & 194 & $\underline{213}$ & $\underline{235}$ & $\underline{256}$ & 261 & 274 & 281 & $\underline{1}$ & 0 -sec & 19 \\
\hline $\mathrm{L}_{5}$ & $\overline{5}$ & & & 19 & 90 & 113 & & & 179 & 183 & 195 & 214 & 236 & 257 & 262 & 275 & 282 & 2 & $16-\mathrm{s}$ & 2 \\
\hline $\mathrm{L}_{6}$ & 6 & & & 20 & 9 & & 124 & 156 & 180 & 184 & 196 & 215 & 237 & 258 & 263 & 276 & 283 & 3 & & 2 \\
\hline $\mathrm{L}_{7}$ & 1 & 1 & & 2 & 92 & 115 & 125 & 157 & 181 & 185 & 197 & 216 & 238 & 259 & 264 & 277 & 284 & $\underline{4}$ & $16-\mathrm{s}$ & 2 \\
\hline $\mathrm{L}_{8}$ & 8 & & $\underline{16}$ & & 9. & 116 & 126 & 158 & $\underline{182}$ & 186 & 198 & 217 & 239 & 260 & 265 & 278 & 285 & 5 & ant & 2 \\
\hline $\mathrm{L}_{9}$ & 9 & & 17 & & 94 & 117 & $\underline{127}$ & 159 & 183 & 187 & 199 & 218 & 240 & $\underline{261}$ & 266 & 279 & 286 & 6 & & 2 \\
\hline $\mathrm{L}_{10}$ & & & 18 & & 95 & 118 & 128 & 160 & 184 & 188 & 200 & 219 & 241 & 262 & 267 & 280 & 287 & 7 & & 2 \\
\hline $\mathrm{L}_{11}$ & 1 & & $\underline{19}$ & & 96 & 119 & 129 & 161 & 185 & 189 & 201 & 220 & 242 & 263 & 268 & 281 & 288 & 8 & $16-s$ & 2 \\
\hline $\mathrm{L}_{12}$ & 12 & & & & 9 & 120 & 130 & 162 & 186 & 190 & 202 & 221 & 243 & 264 & 269 & 282 & 289 & 9 & & 2 \\
\hline $\mathrm{L}_{13}$ & & & & & 98 & 121 & 131 & 163 & 187 & 191 & 203 & 222 & 244 & 265 & 270 & 283 & 290 & 10 & & 2 \\
\hline $\mathrm{L}_{14}$ & 14 & 15 & & & 99 & $\underline{122}$ & 132 & 164 & 188 & 192 & 204 & 223 & 245 & 266 & 271 & 284 & 291 & 11 & & 2 \\
\hline $\mathrm{L}_{15}$ & 15 & 16 & & 25 & 100 & 123 & 133 & 165 & 189 & $\underline{193}$ & 205 & 224 & 246 & 267 & 272 & 285 & 292 & 12 & & 2 \\
\hline $\mathrm{L}_{16}$ & 16 & $\frac{27}{17}$ & & 30 & 101 & 124 & 134 & 166 & 190 & 194 & 206 & 225 & 247 & 268 & 273 & 286 & 293 & 13 & & 2 \\
\hline $\mathrm{L}_{17}$ & 17 & $18^{*}$ & & 3 & 102 & 125 & 135 & 167 & 191 & 195 & 207 & 226 & 248 & 269 & 274 & 287 & 294 & 14 & & 2 \\
\hline $\mathrm{L}_{18}$ & 18 & 19 & & 32 & 103 & 126 & 136 & 168 & 192 & 196 & 208 & 227 & 249 & 270 & 275 & 288 & 295 & 15 & 17 -secant & 2 \\
\hline $\mathrm{L}_{19}$ & 19 & 20 & & & $\underline{104}$ & $\underline{127}$ & 137 & 169 & $\underline{193}$ & 197 & 209 & $\underline{228}$ & $\underline{250}$ & $\underline{271}$ & $\underline{276}$ & 289 & 296 & 16 & ecant & 19 \\
\hline $\mathrm{L}_{20}$ & $\overline{20}$ & 21 & & & 105 & 128 & 138 & 170 & $\underline{194}$ & 198 & 210 & 229 & 251 & 272 & 277 & 290 & 297 & 17 & 16-secant & 2 \\
\hline & & & & & & 29 & 139 & 171 & 195 & 199 & 211 & 230 & 252 & 273 & 278 & 291 & 298 & 18 & 17-secant & \\
\hline
\end{tabular}




\section{REFERENCES}

[1] Ball , S.(2004) “An Introduction to Finite Geometry ”,PP. 1-63.

[2] D' Agostini, E. (1980) "Sulla caratterizzazione delle (k, n; f)-calotte di tipo (n-2,n)", Atti sem. Mat. Fis. University. Modena, XX1X, PP.263-275.

[3] D' Agostini, E. (1981) "On caps with weighted points in PG (2,q)", Discrete Mathematics 34,PP.103-110.

[4] Hammed , F.K. (1989) "Weighted (k,n)- arcs in the projective plane of order nine " Ph.D.Thesis, University of London.

[5] Hirschfeld, J. W. P. (1979) "Projective Geometries Over Finite Fields" Oxford.

[6] Mahmood, R.D. (1990) "(k,n;f)-arcs of type $(n-5, n)$ in PG(2,5)" M.Sc. Thesis, College of Science, University of Mosul.

[7] Mohammed, M.J. and Mahmood. R. D. (1995) “ (k, n; f)-arcs in Galois plane of order seven" Basrah J.science, Vol.13, No.1, 49-56.

[8] Wilson, B. J. (1986) “ (k, n; f)-arc and caps in finite projective spaces”, Annals of Discrete Mathematics 30, PP.355-362. 